\title{
Local Annealing of Cold Rolled Aluminum Sheets by LASER Treatment
}

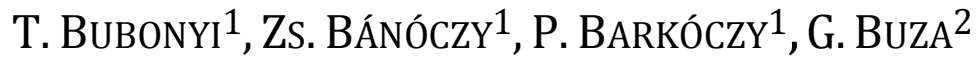 \\ ${ }^{1}$ University of Miskolc, Institute of Physical Metallurgy, Metalforming and Nanotechnology, \\ ${ }^{2}$ Budapest University of Technology and Economics, Department of Automotive Technologies \\ fembubo@uni-miskolc.hu
}

Abstract. LASER treatment widely used in material processing technologies. The annealing is not the typical application of the LASER treatment, but this is possible to apply in case of cold deformed metals. In the article a cold rolled EN AW 8006 aluminum sheet is annealed by LASER treatment. The microstructure of the annealed sheets is observed by optical microscopy. An existing cellular automata simulation of recrystallization process is modified to study the LASER annealing. The observed microstructure and the simulated results are compared to determine the further development of the developed automaton.

\section{Introduction}

LASER is widely used in materials processing. The main application areas are the cutting, the welding, surface treatments as alloying, hardening and remelting [1]. LASER treatment is widely used in case of steel, but there are different applications in aluminium processing too [2,3]. The main advantage of the LASER heating the large energy density of the beam, so the heating rate and transmitted energies are large. Therefore, the heating rate of the surface is fast. The transmitted heat is conducted toward the bulk with a finite rate. So, with the adjustment of the LASER power it is possible to melt or heated up the surface in solid state. Another flexibility of the process that the LASER beam can be moved by optical system, which makes it easy and fast.

One challenge in the LASER treatment of the aluminium parts, that the aluminium reflects more then $90 \%$ of the intensity of the LASER beam [4]. Therefore, it is necessary to use a (graphite) layer which changes this property of the aluminium, and it can involve most of the energy.

The dislocation density of the aluminium sheets increasing during cold rolling. This increases the energy of the metal. This excess energy releasing during heating up the cold rolled aluminium sheets whit the recovery and recrystallization [5]. The recovery is a typical process in a deformed low alloyed aluminium. The dislocation structure is reorganized to a lower spatial configuration [6]. This process is could not observe in the microstructure. During the recrystallization, a new nuclei form and grow in the deformed microstructure and rebuild it to an equaxial grain structure [7]. The temperature of the heat treatment, therefore the heating rate, has a strong effect to the grains size. Generally, the heat treatment in higher temperature causes finer grain size. The recovery in the deformed aluminium is a 
fast process, but not so sensitive to the temperature as the recrystallization. So, the high heating rate favours the recrystallization.

The LASER treatment could be an annealing of the cold rolled aluminium sheets. With the LASER it is possible to heat up the deformed sheets whit extremely high rate. This article shows what happens in the microstructure of the LASER annealed aluminium sheet.

Cellular automaton is one popular mathematical method to simulate the recrystallization process [8]. A simple algorithm can reflect the complex nature of the recrystallization processes. Additionally, a wide variety of the local effects could be considered with this method. One problem in the simulation of LASER annealing is the originally static universe of the automata. Either the sheets moving under the LASER beam, or the LASER beam moves on the surface of the aluminium sheet during the treatment. One solution is a large universe, which means a large computation time. Another possibility is the moving grid [9].

The moving grid is one of the boundary conditions and typically used by tribological simulations. During the method the state of the cells in one boundary of the universe are erased and the state of the cells are shifted by one toward the empty cells. This shift remains empty cells at the opposite boundary of the cellular automata universe. The state of the empty cells is determined by different rules which depend on the simulated processes. The whole process is repeated in every time step. This boundary condition simulates the relative movement of the material [10]. This method is used to study transient or steady state processes.

This articles also study the application of the cellular automaton in the simulation of the LASER annealing of the cold rolled aluminium sheets.

\section{Materials and methods}

Hot rolled commercial EN AW 8006 aluminum sheet is cold rolled from $7 \mathrm{~mm}$ to $2.33 \mathrm{~mm}$ width by a Von-Roll experimental rolling stand. The rolled sheet is LASER treated by a DY 027 Nd YAG diode LASER. The maximal power of the LASER machine is $2.7 \mathrm{~kW}$ and wavelength of the light is $1.064 \mathrm{~nm}$. Before the treatment the surface of the sheet is covered by carbon spray. The sheet is fixed between copper slabs to decrease the risk of heat accumulation in the sheet (figure 1.)

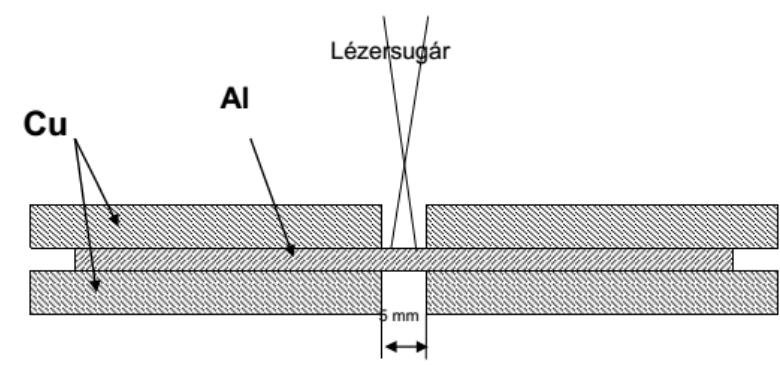

Figure 1. The set-up of the LASER annealing. The alumina sheet fixed between copper slabs the decrease the risk the heat accumulation in the sheet. 
The size of the spot in the surface was $2 \mathrm{~mm}$ and the applied power was $900 \mathrm{~W}$. The velocity of the beam was $500 \mathrm{~mm} / \mathrm{min}$ and the treated length was $800 \mathrm{~mm}$. The sheet is treated perpendicular to the rolling direction. Argon was used as a protective atmosphere.

Samples taken from the treated volume, and the cross section of the sheet is prepared to metallographic investigation. Mechanical grinding ( $\mathrm{SiC}$ ) and polishing ( $3 \mu \mathrm{m}$ diamond) are used in preparation. The polished surface was electrochemically etched by Barker's reagent. The sample were studied with optical microscope under polarized illumination. Mosaic image is taken by a Zeiss AxioImager microscope (Figure 2).

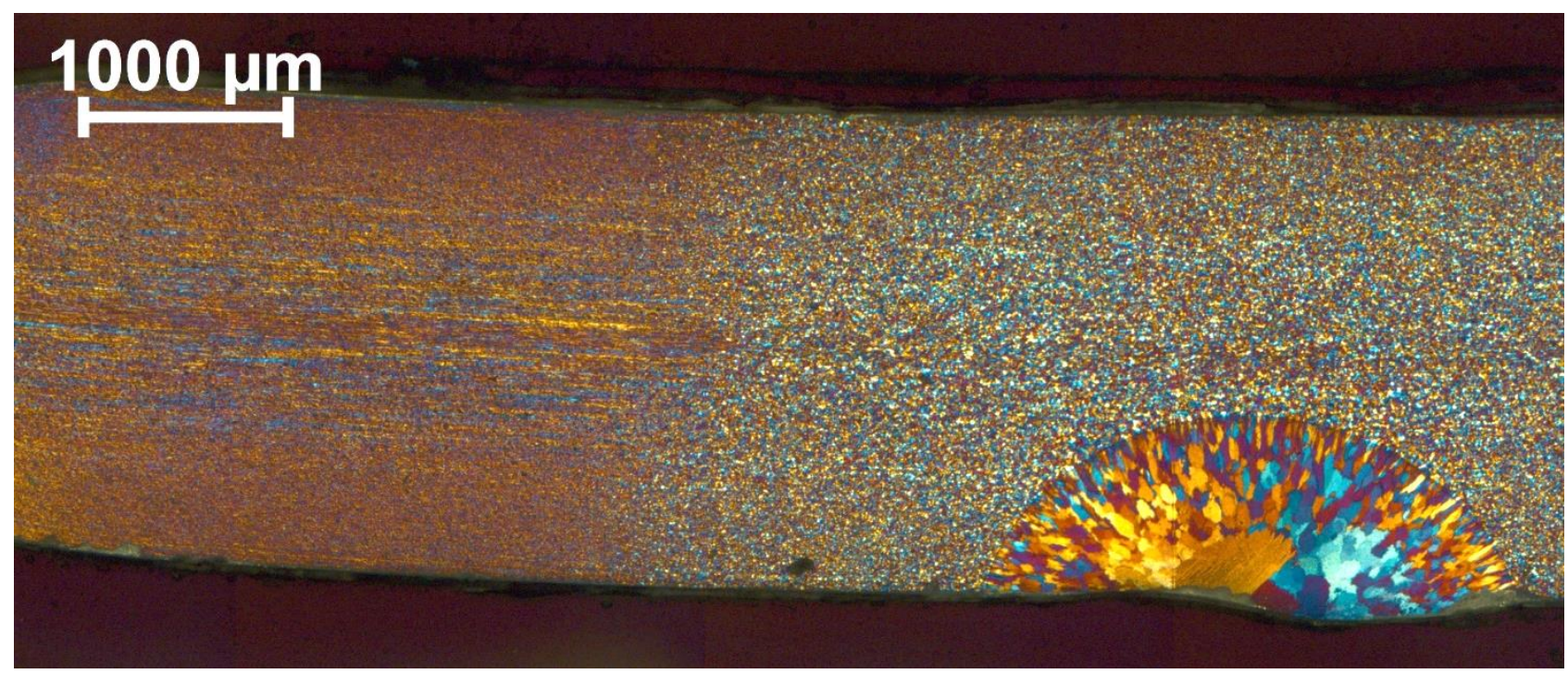

Figure 2. Microscopic image taken from the cross section of the LASER annealed EN AW 8006 sheet.

The cellular automata simulation of the recrystallization is published elsewhere [11]. This automaton was exceeded by the moving grid.

\section{Results and discussion}

Figure 2 shows the microstructure of the LASER annealed EN AW 8006 cold rolled sheet. On the lefthand side of the image the deformed structure can be discovered with the elongated grains. The position of the LASER spot also can be discovered easily because the material of the sheets was melted in a small $(\sim 0.8 \mathrm{~mm})$ extent. Large crystallized grains build up the pool. A large heat affected zone formed around the spool with small recrystallized grains. The heat affected zone covers the whole cross section. Just a thin partially recrystalized volume can be found at the boundary of the heat affected zone. The high LASER power proved large temperature and fast heating around the pool which favoured the recrystallization, and small grains are formed.

The developed cellular automaton is modified. Three-dimensional universe is used with $50 \times 50 \times 50$ cells. Originally all cell has a deformed state which means $10 \mathrm{~kJ} /$ cell stored energy. The activation 
energy of nucleation was $50 \mathrm{~kJ} / \mathrm{cell}$, and the activation energy of the growth process was $30 \mathrm{~kJ} / \mathrm{cell}$. Although the recovery could be a fast process in the annealed alloy, in LASER annealing the recrystallization is the determinative process. The effects of the recovery were neglected. The specific energy of the high angle grain boundaries was $10 \mathrm{~kJ} /$ cell side. These data were not scaled to EN AW 8006, just the ability of the automaton was tested.

The temperature distribution of a moving point heat source calculated by Equation 1 from cell to cell. $T$ is the temperature of the given cell, $T_{0}$ is the original temperature of the sheet, $P$ is the LASER power, $v$ is the velocity of the beam, $x$ and $r$ is the distance from the spot. Figure 3 shows the calculated temperature distribution in the universe.

$$
T=T_{0}+\frac{P}{4 \pi \lambda r}\left(\frac{v}{2 a}(x-r)\right)
$$
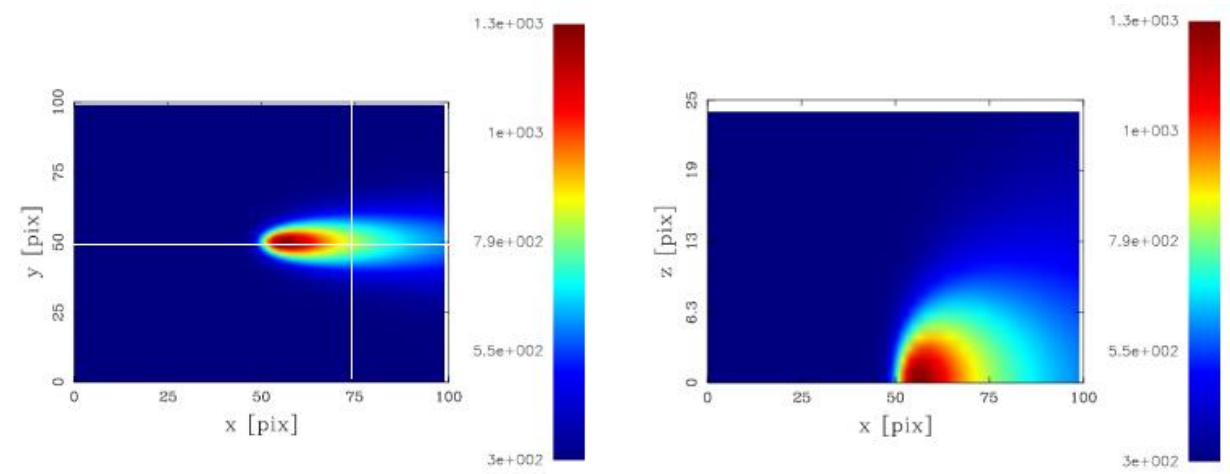

Figure 3. The calculated temperature distribution in the universe of the cellular automaton. The left image show $s$ the temperature distribution at the surface of the sheet. The right image shows the temperature distribution at section along the movement of the beam. The highest temperature values show the position of the spot.

The temperature distribution cannot calculate by arbitrary length units, so the size of the universe is fixed. This means another scaling strategy which was published in [12]. The moving grid method is applied. If the universe is deemed as a cartesian coordinate system as in figure 3 , the state of the cells in $x=0$ plane is erased. All cells got the state of its right neighbour. The state of the cells in $x=49$ plane became deformed. This means that the sheet moves in -x direction under the spot/beam.

Figure 4 show the microstructure which formed after 50 step of the cellular automata calculation. The upper left side image shows the $y=25$ section, which is parallel to the movement of the beam. This shows, that the nucleation started at the front of the spot in the heat affected zone. The recrystallization is continuous in this zone. The black arrow shows the position of the spot. The lower right image shows the full heat affected zone after 50 simulation steps. The fully and partially recrystallized area and the new nuclei also formed by the automata. 


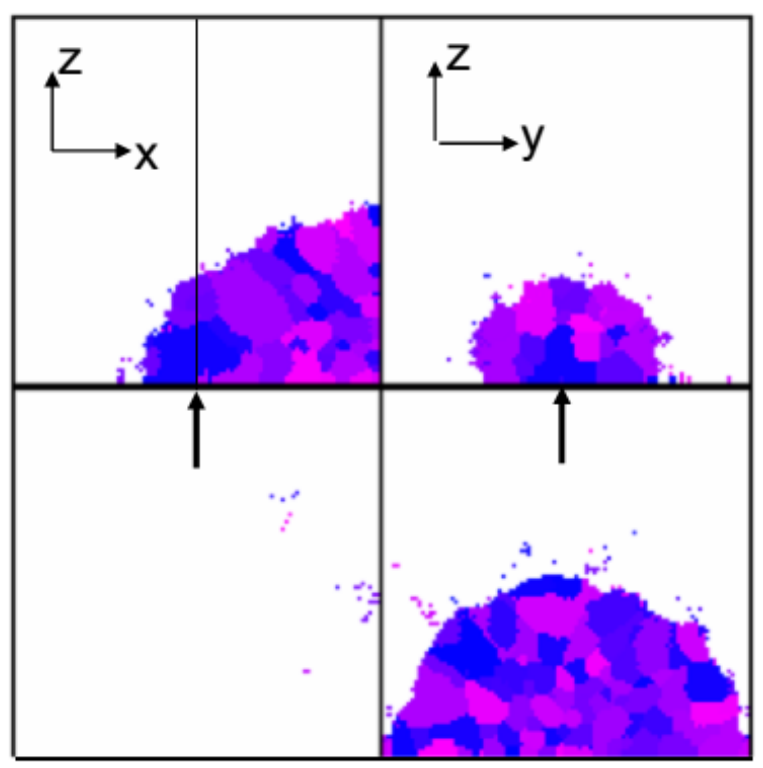

Figure 4. The calculated microstructure from different section of the universe. Upper right section is the $y=25$. Upper left is the $x=25$ section and the lower right is the $x=49$ section.

\section{Summary}

Cold rolled EN AW 8006 sheet is heated up by LASER beam. Around the spot, in a small extent, the material of the aluminium sheet was molten, the crystallized into large grains. round the pool, in a heat affected zone, a large extent of recrystallization was observed. The recrystallized volume is built up by small ekviaxial grains. A thin partially recrystallized layer exists around the recrystallized volume.

A cellular automata simulation is developed to calculate the grain structure. The cellular automaton also calculates the recrystallized grains, and the partially recrystallized layer. The introduced cellular automaton cannot calculate the melting and solidification. It is necessary to excess the calculation with it. The temperature distribution is calculated by the analytic solution of a moving point source at the surface. The application this solution fixed the length scale in the cellular automata universe. An effective scaling strategy was developed earlier to this kind of automata, but it is necessary to modify according to the mentioned constraint. But the automaton with moving grid is a proper solution of the introduced problem.

\section{Acknowledgements}

„SUPPORTED BY THE ÚNKP-18-2-I NEW NATIONAL EXCELLENCE PROGRAM OF THE MINISTRY OF HUMAN CAPACITIES"

"The described article/presentation/study was carried out as part of the GINOP-2.3.2-15-2016-00027 "Sustainable operation of the workshop of excellence for the research and development of crystalline and amorphous nanostructured materials" project implemented in the framework of the Szechenyi 2020 program. The realization of this project is supported by the European Union." 
The described research was also supported through the National Research, Development and Innovation Office - NKFIH K119566 project.

\section{References}

[1] C.W. Draper - P. Mazzoldi (Eds.), Laser Surface Treatment of Metals, Springer

[2] B.S. Yilbas - A.F.M. Arif - C. Karatas - K. Raza (2009) Laser treatment of aluminum surface: Analysis of thermal stress field in the irradiated region. Journal of Materials Processing Technology. 209 pp. 77-88.

[3] T.M. Yue - L.J. Yan - C.P. Chan - C.F. Dong - H.C. Man - G.K.H. Pang (2004) Excimer laser surface treatment of aluminum alloy AA7075 to improve corrosion resistance. Surface and Coatings Technology. 179. pp. 158-164.

[4] K. Bernolák, A Fény, Műszaki Könyvkiadó

[5] J. D. Verhoeven, Fundamentals of Physical Metallurgy, Willey \& Sons

[6] H.P. Stüwe - A.F. Padilha - F. Siciliano Jr (2002) Competition between recovery and recrystallization. Materials Science and Engineering A333. pp. 361-367

[7] P. Cotteril - P.r. Mould: Recrystallization and Grain Growth in Metals. Surrey University Press.

[8] K. Janssens - G. Frans - D. Raabe - B. Nestler - E. Kozeschnik - M.A. Miodownik (2010) Computational Materilas Engineering. Academic Press.

[9] H. Kloss - R. Wasche (2009) Analytical approach for wear pre diction of metallic and ceramic materials in tribological applications. Wear 266. pp. 476-481.

[10] A.I. Dmitriev - W. Österle (2010) Modeling of brake pad-disc interface with emphasis to dynamics and deformation of structures. Tribology International. 43 pp. 719-727.

[11] P. Barkóczy - A. Roósz - J. Geiger (2003) Simulation of Recrystallization by Cellular Automaton Method. Materials Science Forum. 414. pp. 359-363.

[12] Sz. Gyöngyösi, P. Barkóczy (2013) Scaling cellular automaton simulations of shortrange diffusion processes. Materials Science Forum. 729. pp.150-155. 